\title{
NOTICES
}

\section{THE 19TH AUTUMNAL MEETING OF THE JAPANESE SOCIETY OF GASTROENTEROLOGY}

The 19th Autumnal Meeting of the Society will be held under the chairmanship of Professor Tsuneo Shiratori, M.D., Department of Surgery, Nara Medical University, at the Nara Bunka Kaikan Hall, Nara City, October 18 to 20,1977 , the program of which is as below:

1. Invited lecture:

The metabolism of bile acid Prof. Alan F. Hofmann, (Assoc. Director of Gastroenterology

Unit, Mayo Clinic, U.S.A.)

\section{Chairman's lecture:}

Operability and the results of ulcerative colitis

Dr. Tsuneo Shiratori (Nara Med. Univ.)

3. Symposium:

(1) Bile acid and the digestive diseases

Moderators: Dr. H. Nagashima (Okayama Univ.)

Dr. F. Nakayama (Kyushu Univ.)

(2) Alimentation and the digestive diseases

Moderators: Dr. T. Maki (Tohoku Rosai Hospital)

Dr. M. Ishikawa (Yamagata Univ.)

(3) Clinic of gastric cancer in young people

Moderators: Dr. S. Ashizawa (Tokyo Medical Univ.)

Dr. S. Majima (Kyoto Pref. Univ. of Med.)

(4) Crohn's disease and related troubles

Moderators: Dr. S. Yamagata (Tohoku Univ.)

Dr. E. Yukawa (Yukawa G.I. Hospital)

(5) Magnifying observation and pathophysiology of the mucosa of the digestive tract

Moderators: Dr. T. Takemoto (Yamaguchi Univ.)

Dr. K. Kawai (Kyoto Pref. Univ. of Med.)

\section{Panel Discussion:}

The method of education on endoscopic examination

Moderators: Dr. T. Miyake (Tenri Yorozu Hospital)

Dr. T. Hayashi (Nihon Univ.)

\section{THE 64TH ANNUAL MEETING OF THE JAPANESE SOCIETY OF GASTROENTEROLOGY}

The 64th Annual Meeting of the Society will be held under the chairmanship of Professor Takeo Wada, M.D., Ist Department of Internal Medicine, Sapporo Medical College, at the Hokkaido Kosei Nenkin Kaikan Hall, Sapporo City, Hokkaido, May 22 to 24, 1978.

Further information of the meetings may be obtained from: The Secretariat, The Japanese Society of Gastroenterology, c/o Gyosei Bldg., 4-12 Ginza 7-chome, Chuo-ku, Tokyo, 104 Japan. 